\title{
Myopathy in Primary Systemic Amyloidosis
}

\author{
M.E. Roke, W.F.E. Brown, D. Boughner, L.C. Ang, G.P.A. Rice
}

\begin{abstract}
Involvement of the peripheral nervous system by amyloidosis is common. It is less well recognized that amyloid can directly infiltrate and weaken skeletal muscle. We report a case of a 73-year-old woman, known to have cardiac amyloidosis, who developed profound weakness secondary to amyloid myopathy. Review of the 8 other well documented cases in the literature has revealed a rather homogeneous syndrome. Proximal weakness, muscle stiffness, pseudohypertrophy and myalgia constitute the principal features. This syndrome usually develops in cases with well recognized generalized amyloidosis. Amyloid is deposited within the basal lamina of blood vessels and muscle fibers.
\end{abstract}

RÉSUMÉ: La myopathie dans l'amyloïdose primaire systémique L'envahissement par l'amyloïdose du système nerveux périphérique est fréquent. Il est moins connu que la substance amyloïde peut infiltrer directement le muscle squelettique et l'affaiblir. Nous rapportons le cas d'une femme âgée de 73 ans, connue comme porteuse d'une amyloïdose cardiaque, qui a développé une faiblesse extrême secondaire à une myopathie amyloïde. Une revue des 8 autres cas bien documentés déjà publiés a montré un syndrome plutôt homogène. Les principales caractéristiques cliniques sont la faiblesse proximale, la raideur musculaire, la pseudo-hypertrophie et la myalgie. Ce syndrome se développe habituellement chez des patients porteurs d'une amylö̈dose généralisée bien identifiée. La substance amyloïde se dépose dans la membrane basilaire des vaisseaux sanguins et des fibres musculaires.

Can. J. Neurol. Sci. 1988; 15;314-316

Weakness in systemic amyloidosis can result from neuropathy and debility from congestive heart failure. ${ }^{1}$ Less well recognized is weakness from amyloid infiltration into muscle ${ }^{2-4}$. We report such a case and have reviewed the literature.

\section{CASE REPORT}

A 73-year-old woman with clinically established cardiac amyloidosis developed difficulty walking and reaching overhead over a 2 week period in June 1986. Her weakness progressed so that she could walk only 100 feet. She experienced pain in her shoulders, arms, hips and thighs, especially following activity and at night.

She had developed congestive heart failure one year previously, and was found to have a restrictive cardiomyopathy. Endomyocardial biopsy revealed amyloid fibrils. She was treated with digoxin, furosemide and captopril. Her previous medical history was unremarkable except for chronic hypertension and diverticulitis. The family history was unremarkable.

On physical examination, she looked chronically ill. Blood pressure measured $110 / 60 \mathrm{~mm} \mathrm{Hg}$, the pulse was 76 beats per minute and the respiratory rate was 14 . A grade II/VI ejection systolic murmur was audible at the left sternal border. The apical impulse was sustained and displaced to the left and the second heart sound was split. The jugular venous pressure measured $6 \mathrm{~cm}$. The liver span was normal but the splenic tip was palpable.

Neurological examination revealed a generalized decrease in muscle bulk which was most pronounced proximally, especially in the gluteus maximus. The calves, however, were enlarged and had a doughy consistency. Moderately severe proximal muscle weakness was evident and this progressed over a six month observation period to involve all muscle groups, including neck flexors, pelvic and shoulder girdles, and the trunk. She could not sit without assistance nor could she raise her legs against gravity. Deep tendon reflexes were normal. Sensory examination was unremarkable.

Serum chemistry, renal function indices, complete blood count, thyroid function immunoglobulin levels, prothrombin time, and partial thromboplastin time were normal. The erythrocyte sedimentation rate was 30. Total CPK measured 420 with an MM fraction of 420 (normal 26-40). Total lactate dehydrogenase was 595 (normal 203-378). Protein electrophoresis revealed a slight decrease in albumin. Serum and urine

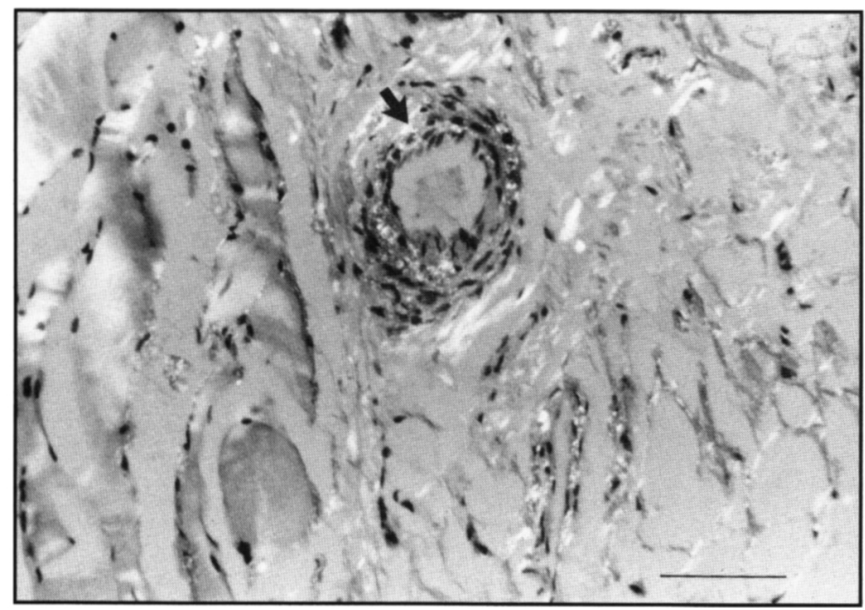

Figure I - The arteriole wall and perivascular tissue in the perimysium of skeletal muscle show's birefringence with apple-green colour with Congored stain (arrow). (Note that the surrounding collagen fibers are a different colour under polarization). (Congo Red; Bar = $50 \mu \mathrm{m})$.

From the Department of Clinical Neurological Sciences, University Hospital, London

Received December I, 1987. Accepted March 11, 1988

Reprint requests to: Dr. G.P.A. Rice, Clinical Neurological Science Department, University Hospital, P.O. Box 5339, Postal Station A, London,

Ontario, Canada N6A 5A5 


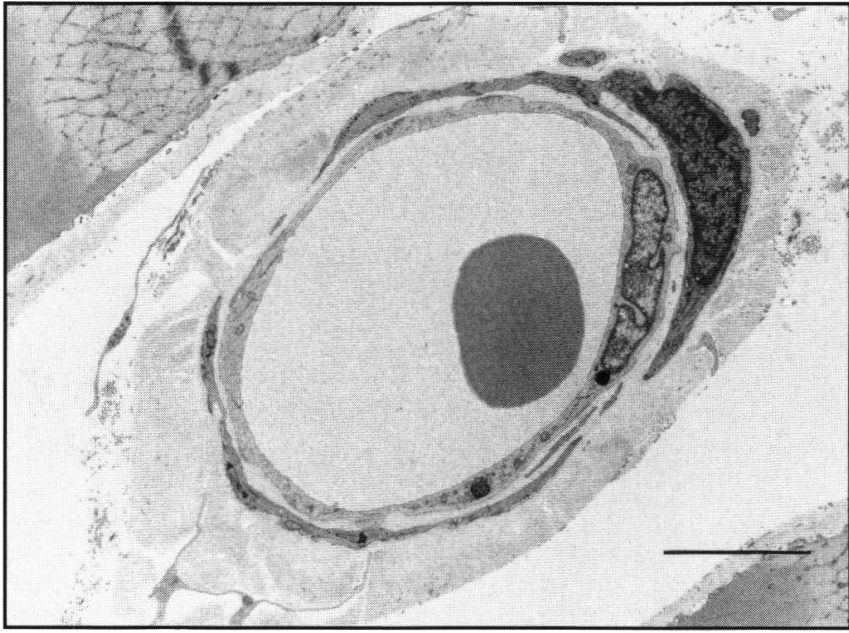

Figure 2. - Electron micrograph of a capillary within the perimysium showing amyloid deposition along the basement membrane resulting in thickening of the capillary wall. Amyloid is also seen along the basal lamina of individual skeletal muscle fibers. $(\mathrm{Bar}=1 \mu \mathrm{m})$.

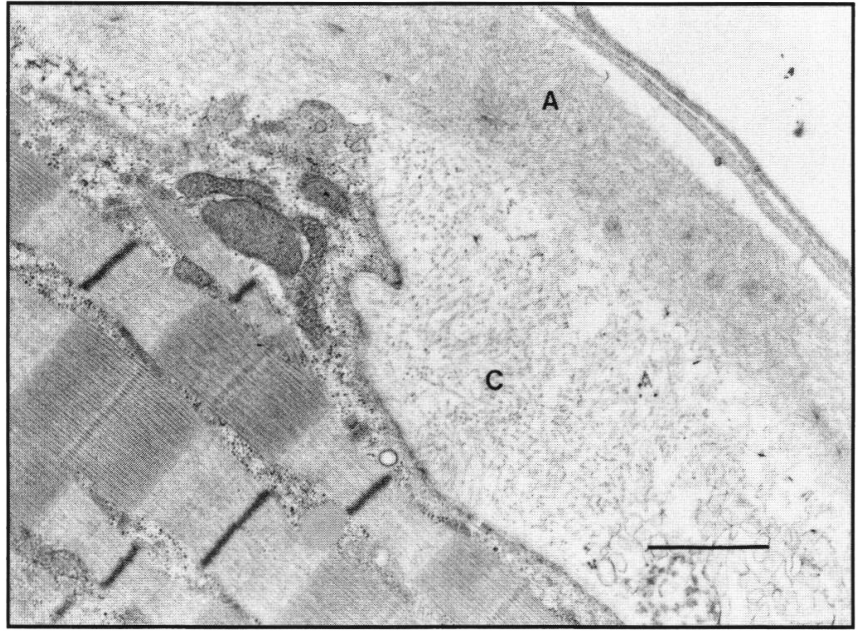

Figure 3-Left-lower corner shows myofibrils which appear normal. The basal lamina is thickened by deposition of amyloid (A) fibrils. Collagen fibers are identified by $(C) .(B a r=1 \mu \mathrm{m})$.

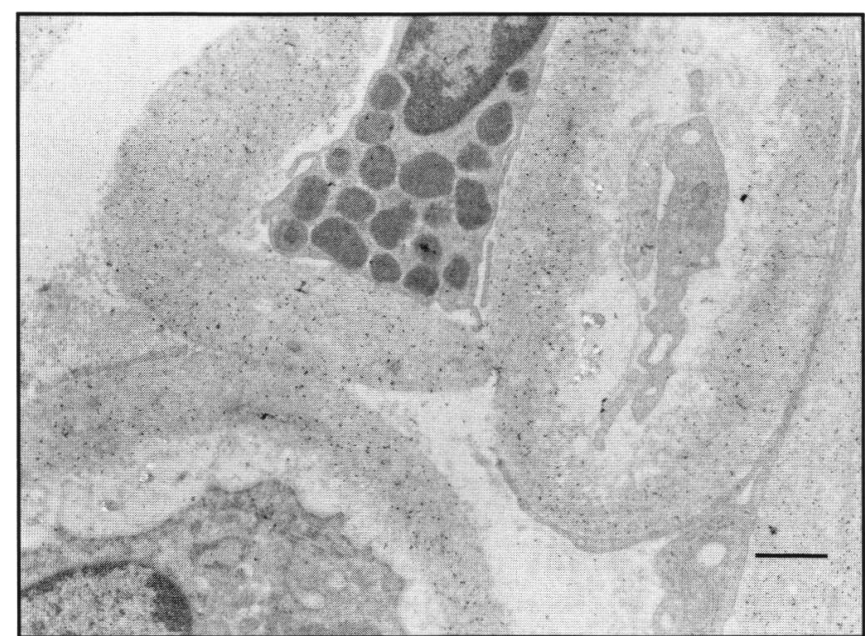

Figure 4-Colloidal immunogold technique (12) reveals lambda light chains within the amyloid deposits. The positivity is indicated by multiple, electron-dense, black, grain-like particles. A mast cell is present in the upper centre portion, and a capillary is seen on the right side. $(\mathrm{Bar}=(\mu \mathrm{m})$. immunoelectrophoreses revealed free monoclonal lambda light chains. Bone marrow aspiration was normal, without lymphocytosis or plasmacytosis.

Sensory and motor conduction velocities in the median nerve were normal. The electromyographic abnormalities were maximal in the iliacus. There was increased insertional activity, fibrillation potentials, and positive sharp waves. Brief duration small amplitude motor unit potentials were seen in addition to hypercomplex motor unit potentials. linked potentials and bizarre repetitive discharges. The recruitment pattern was myopathic in nature.

Paraffin and cryostat sections of the right deltoid muscle revealed mild thickening of the perimysial arterioles and capillaries as well as i moderate increase in perimysial connective tissue. Scattered atrophic fibers were seen. There was no evidence of necrosis, regeneration or inflammation (not shown). The intramuscular nerves appeared to be normal. Congo Red staining confirmed the presence of amyloid fibrils in the walls of small arterioles and capillaries and within the basal lamina of individual muscle fibers (Figure I). ATPase immunohistochemistry revealed Type II fiber atrophy. Immunohistochemistry with a peroxidase-antiperoxidase technique revealed lambda light chains. No prealbumin was identified. Electron microscopy revealed unbranched fibrils ( $10 \mathrm{~nm}$ diameter) consistent with amyloid, within and around blood vessel walls and within the basal lamina of muscle fibers (Figures 2,3). These fibrils reacted with an antibody specific for lambda light chains, as shown by immunogold technique (Figure 4).

\section{DisCUSSION}

This case exemplifies a rare neurological complication in systemic amyloidosis. 1.2 Although amyloid fibrils can be deposited in virtually any organ, progressive myopathy secondary to deposition in muscle occurred in only 3 of 227 patients reviewed in a recent Mayo Clinic series. ${ }^{1}$

Table 1: Clinical Features

\begin{tabular}{|c|c|c|c|c|c|c|}
\hline Author & & $\begin{array}{l}\text { Number } \\
\text { of Cases }\end{array}$ & $\begin{array}{c}\text { Systemic } \\
\text { Deposition }\end{array}$ & $\begin{array}{l}\text { Muscle } \\
\text { Bulk }\end{array}$ & Weakness & Mỵalgia \\
\hline Lubarsch & (5) & 1 & + & $?$ & + & + \\
\hline Reckenmiller & (6) & 1 & $+t$ & Decrease & ++ & + \\
\hline Martin & (7) & 1 & ++ & Increased & ++ & + \\
\hline Lange & (11) & 1 & $++t$ & Increased & - & + \\
\hline Whitaker & (3) & 1 & ++ & Increased & ++ & - \\
\hline Miyasacki & (9) & 1 & +++ & Increased & $+1-$ & + \\
\hline Ringel & (4) & 1 & +++ & Increased & + & ++ \\
\hline $\mathrm{Li}$ & (10) & 1 & +++ & Increased & + & + \\
\hline
\end{tabular}

This patient first developed symptoms at the age of 73. The age of onset in the other cases ranged from 38 to 70 . The presenting symptoms, as in this case, have included fatigability, muscle stiffness and pain, and generalized or proximal weakness (Table 1). Weakness was the commonest clinical feature. Pseudohypertrophy has also been commonly described. Our patient appeared to have wasting in the proximal musculature and hypertrophy in the calf muscles. Sensory abnormalities and reflex changes have not occurred either in the proposita or in the other cases. The rate of progression has been variable, with progression occurring over months or years.2-10 Most patients have had obvious clinical evidence of systemic amyloidosis, with macroglossia, dysphagia, hoarseness or difficulty in speech, gastrointestinal symptoms and swelling or stiffness of small joints. $3.4,7,8,9,10,11$

The electrophysiological studies in this case and in the reviewed cases suggested a myopathic process. Abnormal insertional activity, brief duration, small amplitude polyphasic action potentials, and a low amplitude complex recruitment pattern 
have been reported commonly. In most reports, nerve conduction velocities have been normal.

The pathological features have commonly included a variable degree of muscle atrophy. Some have reported a selective atrophy of Type II fibers. The amyloid deposits in muscle appeared to be primarily in the blood vessels (Table 2). These cases appear to be different from the limb-girdle dystrophy described by Bruni et al. ${ }^{8}$ In his case, amyloid deposition was restricted to endomysial blood vessel walls, and was not seen systemically.

\begin{tabular}{lccccc} 
Table 2: Pathology & \multicolumn{1}{l}{} \\
\hline Author & & $\begin{array}{c}\text { Muscle } \\
\text { Atrophy }\end{array}$ & $\begin{array}{c}\text { Location of } \\
\text { Vessel }\end{array}$ & $\begin{array}{c}\text { Amyloid } \\
\text { Perivascular Perimysial }\end{array}$ \\
\hline Lubarsch & $(5)$ & ++ & - & + & + \\
Martin & $(7)$ & ++ & - & + & + \\
Lange & $(11)$ & not specified & - & + & + \\
Whitaker & $(3)$ & + (Type II) & - & + & + \\
Miyasacki & $(9)$ & +++ & - & + & + \\
Ringel & $(4)$ & + (Type II) & + & + & + \\
Li & $(10)$ & +++ & + & + & + \\
\hline
\end{tabular}

There appears to be no cure for this malady. Prednisone therapy was ineffective in 3 cases. 3.4 .8 A number of recent studies have gauged the effect of melphalan and prednisone or colchicine but no significant benefit has been shown. ${ }^{15-18}$

The etiology of primary amyloidosis is unknown. The protein deposits consist of fibrils which are identical to the variable portion of immunoglobulin, representing either an excess deposition or slow removal. Light chain excretion and plasmacytosis (bone marrow) were documented in 3 cases. $3,4,10$

The pathogenesis of the myopathy is also unknown. Muscle contraction could be restricted mechanically by impaired tissue elastance because of the amyloid deposition. Perimysial infiltrations could lead to muscle distortion and atrophy. Perivascular and perimysial connective tissue with deposits might impede the nutrition of muscle and the clearance of metabolic waste products and it is possible that muscle ischemia might occur because of narrowing of arterioles. Some have proposed that amyloid infiltration might impair the propagation of action potentials down the sarcolemma.

Delaporte and colleagues described one patient with a kappa light chain myeloma and muscular hypertrophy in whom amyloid deposits were not demonstrable by Congo Red staining. 19 The kappa immunoglobulin fraction of this patient's serum exhibited a trophic effect on human muscle cells in culture. This might afford an explanation for the hypertrophy in some cases.

\section{REFERENCES}

1. Kyle RA, Greipp PR. Amyloidosis. Mayo Clin Proc 1983; 58: 665683.

2. Baker B and Engel A. Myology. McGraw-Hill, 1986; 887-891; 1029-1036; 2098-2099.

3. Whitaker JN, Hashimoto K, Quinones $M$ et al. Skeletal muscle pseudohypertrophy in primary amyloidosis. Neurology 1977; 27: 47-54.

4. Ringel SP, Chaman HN. Amyloid associated pseudohypertrophy. Arch Neurol 1982; 39: 413-417.

5. Lubarsch D. "Zur kenntnis eingenhohnlicher amyloidablagerumgen" Virchows Arch 1929; 271 : 867-889.

6. Reichenmiller HE, Bundschu HD, Bass L, et al. Progressive muscular dystrophy and pericollagenous amyloidosis. German Medical Monthly 1968; 13: 380-384.

7. Martin JJ, Van Bogaert L, Van Damme J, et al. Sur un pseudomyopathie ligneuse généralisée par Amyloidose primaire endomysio-vasculaire. J Neurol Sci 1970; 11: 147-160.

8. Bruni J, Bilbao JM, Pritzker KPH. Myopathy associated with amyloid angiopathy. Can J Neurol Sci 4(1): 1977; 77-80.

9. Miyasacki K, Murao S, Tsunetoshi S, et al. Primary systemic amyloidosis. Acta Pathol Jpn, 29 (1): 1979; 157-169.

10 Li K, Hizawa K, Morizumi H, et al. Primary Systemic Amyloidosis. Arch Path 1984; 39: 315-322.

11. Lange K. Primary Amyloidosis of Muscle. Southern Med J 1974; 63: 321-323.

12. Bendagen $M$. Protein A-gold electron microscopic immunocytochemistry: methods, applications and limitations. J Electron Microscopy Technique 1984; 1: 243-270.

13. Mair WGP, Tome FMS. Atlas of the ultrastructure of disease of human muscle. (Churchill Livingston, London, 1972).

14. Andrade C. A peculiar form of peripheral neuropathy. Brain 1952; $75 ; 408-427$.

15. Ravid M, Robson M, Kedar I, et al. Prolonged cochicine treatment in four patients with amyloidosis. Ann Int Med 1977; 87: 568570.

16. Kyle RA, Greipp PR. Primary systemic amyloidosis: comparison of melphalan and prednisone versus placebo. Blood, 1978; 52 (4): 818-827.

17. Kyle RA, Greipp PR, Garton JP et al. Primary systemic amyloidosis. Am J Med 1985; 79: 708-716.

18. Zewar D, Pras M, Sohar E, et al. Colchicine in prevention and treatment of the amyloidosis of familial mediterranean fever. $\mathrm{N}$ Eng J Med 314 (16): 1986; 1002-1004.

19. Delaporte C, Varet B, Fardeau M, et al. In vitro myotrophic effect of serum kappa chain immunoglobulins from a patient with kappa light chain myeloma and muscular hypertrophy. J Clin Invest 1986; 78: 922-927. 